\title{
LA COOPERACION ENTRE COMUNIDADES AUTONOMAS \\ El acuerdo entre la Comunidad Autónoma Vasca \\ y la Comunidad Foral de Navarra
}

Juan Cruz Alli

\section{Saludos.}

En primer lugar he de manifestar mi más profundo y sincero agradecimiento a la Universidad por la oportunidad de participar en este acto académico, más por el afecto con que me honran muchos miembros de esta comunidad que por mis méritos personales y académicos. Muchas gracias. Mila esker.

El tema objeto de la exposición puede ser analizado y valorado desde dos perspectivas bien diferentes. Por una parte, desde el marco jurídico constitucional español, con base en la Constitución de 1978 y en los Estatutos de Autonomía, así como en la reducida práctica de tal cooperación dentro del Estado español. Por otra desde la valoración del funcionamiento institucional, como una de las posibilidades que el sistema constitucional encierra de reconocimiento de los hechos diferenciales, de manifestación y ejercicio del autogobierno, así como de consolidación de una forma de Estado regional descentralizado con posibilidades federalizantes. Se ha de constatar que esta segunda perspectiva nos permite apreciar el grado de aceptación del modelo de Estado autonómico, el alcance real de las llamadas al desarrollo del autogobierno, la solidez de los referentes de identidad cuando se vinculan a los procesos institucionales. Es de toda evidencia que la fe en el autogobierno se manifiesta en la utilización máxima de las potencialidades constitucionales y estatutarias. Por el contrario, su invocación resulta retórica cuando por prejuicios, partidismo o simple complejo de inferioridad, se produce el rechazo de todo aquello que se desconoce o ignora, exponente de una mentalidad cerrada y medrosa que, como decía Machado, «envuelta en sus andrajos, desprecia cuanto ignora». 


\section{Introducción sobre la cooperación horizontal en los sistemas federales y descentralizados}

En los Estados centralistas la distribución de competencias y la cooperación entre las distintas administraciones territoriales se fundamenta en el principio de unidad, que se instrumentaliza en las técnicas de la jerarquía y la tutela. La jerarquía implica la subordinación al superior, quien organiza, dirige y supervisa, excluyendo cualquier autonomía. La tutela tiene menos entidad, pero implica controles de legalidad y oportunidad del ente tutelante sobre el tutelado, al que se le reconoce un cierto nivel de autonomía, pero dentro de una cuasi subordinación jerárquica.

Por el contrario, en los modelos federales o unitarios descentralizados, la distribución de competencias implica el reconocimiento de distintos ámbitos de poder político autónomo, sin dependencia jerárquica. La autonomía «hace referencia a un poder limitado. En efecto, autonomía no es soberanía, y dado que cada organización territorial dotada de autonomía es una parte del todo, en ningún caso el principio de autonomía puede oponerse al de unidad, sino que es precisamente dentro de éste donde alcanza su verdadero sentido» (S.TC. 4/1981). Se trata de una autonomía política con potestades legislativas y gubernamentales, no de una mera autonomía administrativa, que hace necesaria la cooperación entre todos los gobiernos territoriales para la resolución de los problemas comunes, sin que la supraterritorialidad de los mismos exija la presencia de la Administración central. Este es el fundamento de la doctrina del federalismo cooperativo, que ha tenido manifestaciones anteriores en la cooperación horizontal entre los gobiernos infraestatales que en la vertical entre el Estado y aquellos. Se trata de un concepto político que asume la existencia de competencias compartidas por diversos poderes, que obligan a una necesaria interdependencia y cooperación ${ }^{1}$. Para González Navarro «hay dos formas de enfrentarse con el hecho de la cooperación entre los diversos poderes: encararlo por su lado positivo, viéndolo como el único medio de frenar la que, de otra forma, se convierte en imparable corriente centralizadora; o bien, verlo por el lado negativo como la forma encubierta que adopta hoy el centralismo» ${ }^{2}$.

1 Muñoz Machado, S.: Derecho Público de las Comunidades autónomas, I, Madrid, 1982, pp. 218-239. Pergola, A. LA: Los nuevos senderos del federalismo, Madrid, 1994, pp. 277 y ss.

${ }^{2}$ González Navarro, F.: Derecho Administrativo Español, I, Pamplona, 1993, p. 361. 
Todos los instrumentos de cooperación parten de la necesidad, apreciada por los órganos de gobierno, de que los problemas superan el ámbito territorial individualizado y exigen soluciones de mayor espacio, así como del reconocimiento de que la autonomía en el ejercicio de las propias competencias exige el acuerdo convencional entre los poderes públicos afectados. Ha de aceptarse que la nueva configuración de la distribución territorial del poder, en modelos federales o regionales descentralizados, «no se entiende ya como separación y mera yuxtaposición de esferas independientes y soberanas de gobierno, actuando cada una sobre un ámbito material propio y exclusivo, sino como colaboración entre los diversos centros de gobierno en la consecución de objetivos de común interés, como participación de todas las instancias en un esfuerzo conjunto para el cumplimiento de todas aquellas funciones y tareas que redundan en beneficio del todo y, con él, de las propias partes» ${ }^{3}$.

Por ello los acuerdos entre Estados miembros de una Federación o entre regiones, si se trata de un Estado unitario descentralizado, son práctica habitual allí donde están consolidados y existe una auténtica conciencia de autogobierno. Podemos afirmar que son algo consustancial con el modelo político-institucional de distribución territorial del poder, cuyo límite es el respeto al orden competencial que establezca la Constitución, dada la indisponibilidad de la titularidad de las competencias. Ello a pesar de que desde las esferas del poder central de los Estados existe una clara desconfianza ante tales iniciativas, tratando de proteger su propio ámbito competencial y de evitar la creación de otros centros de poder que puedan alterar el equilibrio existente. A ello obedecen las medidas de control de los convenios horizontales de cooperación.

\subsection{Estados Unidos de América}

En los Estados Unidos, el artículo 1, sección 10. ${ }^{a}$, apartado 1, de la Constitución dispone que «ningún Estado podrá celebrar Tratados, Alianzas o Confederaciones». En el apartado 3 añade que «ningún Estado podrá, sin el consentimiento del Congreso... celebrar ningún acuerdo o pacto con otro Estado. La autorización del Congreso posibilita los acuerdos, cuyo control ha reducido la jurisprudencia al afirmar que aquélla no es necesaria «para los acuerdos que no tuvieran por objeto

3 Alberti Rovira, E.: Federalismo y cooperación en la República Federal Alemana, Madrid, 1986, p. 358. 
aumentar el poder político de los Estados u oponerse a la justa supremacía del Estado Federal» ${ }^{4}$.

Los convenios entre Estados se han clasificado en las siguientes categorías. Los reguladores de materias importantes para las sociedades, como el agua o el petróleo. Los de áreas metropolitanas para la planificación y gestión de áreas urbanas. Los de cuenca fluvial para la política hidráulica y de desarrollo del conjunto de la cuenca. Los de servicios interestatales para mejorarlos y evitar duplicidades en materias de la competencia estatal como educación, sanidad, policía, asistencia social, etc. ${ }^{5}$

Existen, además, numerosos órganos, organismos e instituciones interestatales de coordinación, unos de deliberación, que dictan resoluciones no vinculantes para los Estados, y otros con facultades decisorias y ejecutivas, vinculantes para los Estados miembros. En este segundo supuesto gozan de personalidad jurídica propia y capacidad para el ejercicio de las competencias ejecutivas que se hayan transferido al organismo común. Su creación no ha planteado cuestiones de constitucionalidad, considerándose algo consustancial con el modelo político y la necesidad de cooperación en condiciones de libertad e igualdad convencionales ${ }^{6}$.

\subsection{República Federal Alemana}

En la Ley Fundamental de Bonn no hay regulación de la materia, pero la práctica ha sido muy rica en fórmulas de coordinación, auxilio y cooperación vertical entre el Bund y los Länder, así como horizontal entre los Länder, siempre que se respete la competencia federal, los límites territoriales y la configuración de los Estados miembros. La coordinación, basada en el acuerdo de voluntades, permite que concierten el ejercicio de sus respectivos poderes y que busquen una orientación conjunta de los criterios de actuación de sus propias competencias ${ }^{7}$.

La coordinación no es una norma de competencia ordenadora de la concurrencia de poderes sobre una misma materia o sector, sino un modo de proceder en el ejercicio de los respectivos poderes, conforme a

4 Santaolaya Manchetti: Descentralización y cooperación, Madrid, 1981, p. 135. Alberti Rovira, E: Federalismo y cooperación en la República Federal Alemana, Madrid, 1986.

${ }^{5}$ LóPEZ-ARAnguren, E.: Federalismo americano: Las relaciones entre poderes en los Estados Unidos, Madrid, 1987, pp. 200-206.

6 Alberti Rovira, E.: Federalismo..., cit., pp. 411-414.

7 Alberti Rovira, E.: Federalismo..., cit., pp. 414 y ss.; 464 y ss. 
un parámetro común, ensamblando actuaciones distintas para conseguir un resultado armónico. Se basa en el respeto de las competencias, ejercitadas con el libre acuerdo de las partes, en total igualdad, sin que ninguna pueda imponer ni criterios ni decisiones mayoritarias, basándose en el consenso y la unanimidad consustanciales con la radical igualdad de quienes voluntariamente deciden coordinar su acción. «La nota esencial de la coordinación es el mantenimiento íntegro de los poderes de las partes y de su capacidad de actuación autónoma en todo momento, sin perjuicio de que se intente el acuerdo sobre el modo de ejercicio de sus respectivos poderes, intento y acuerdo que constituyen el contenido y el objetivo principales, respectivamente, de la coordinación» ${ }^{8}$.

La coordinación horizontal se apoya en órganos comunes creados por acuerdo entre los Länder. Afecta a todos los sectores y materias de su competencia, tanto en el ámbito administrativo como en el legislativo. La coordinación general se produce a través de organismos como la Conferencia de Ministros-Presidentes de los Länder, de naturaleza deliberante. A nivel legislativo por medio de la Conferencia de Presidentes de los Parlamentos estatales alemanes, también de naturaleza deliberante en materias de organización y funcionamientos de las Cámaras. En el ámbito ejecutivo-administrativo existen numerosos órganos de coordinación sectorial, como las Conferencias de Ministros de Finanzas, Economía, Comunicaciones, etc.

El auxilio es un deber de colaboración interadministrativa, basado en la lealtad constitucional a la ordenación de poderes y de competencias. Se traduce en la aportación de medios o en la realización de actividades o servicios en beneficio de otras organizaciones públicas.

La cooperación consiste en una toma conjunta de decisiones, en el coejercicio de las competencias, por varias partes que actúan mancomunadamente. Se trata de una «mancomunización de poderes», del establecimiento de un «régimen de atribución y ejercicio mancomunado de competencias», participando varias instancias en un único sistema de decisión. Su establecimiento se realiza por la Constitución o bilateralmente por acuerdo libre de las partes, quienes no pueden disponer de la titularidad de las competencias sino sólo del modo de ejercicio de las mismas, ya que en otro caso se alteraría el orden competencial. De este modo la cooperación convencional sólo supone un modo conjunto de ejercicio de las competencias, próximo a la coordinación, sin incidir en la titularidad, que está regido por el principio de indisponibilidad del orden de distribución de los poderes. Esta cooperación libre es el

8 Alberti Rovira, E.: Federalismo..., cit., pp. 367-368. 
medio habitual de cooperación horizontal en Alemania, y se instrumenta por medio de convenios y acuerdos, creando órganos comunes. La creación de estos órganos comunes o mixtos es una abundante realidad avalada por la inexistencia de prohibición constitucional y por su propia naturaleza instrumental, que, al no recibir la titularidad de las competencias sino sólo la gestión, no atenta al orden competencial ${ }^{9}$.

\subsection{Federación Helvética}

El artículo 7 de la Constitución suiza prohíbe «toda utilización particular y todo tratado de naturaleza política entre Cantones». «Los Cantones tendrán, en cambio, derecho a concertar entre sí convenios sobre materias objeto de legislación, si bien deberán comunicar dichos convenios a la autoridad federal, la cual si los mismos contienen algo que se oponga a la Confederación o a los derechos de los demás Cantones, estará autorizada a impedir su ejecución. En caso contrario, los Cantones contratantes estarán facultados para recabar para su ejecución la cooperación de las autoridades federales» ${ }^{10}$.

En Suiza también se admiten órganos intercantonales de coordinación, sin facultades decisorias propias y sin capacidad de dictar resoluciones vinculantes, como «lugar de encuentro para intercambiar información, debatir problemas comunes, coordinar actuaciones de modo informal y preparar proyectos concretos de cooperación». Los convenios intercantonales pueden crear órganos ejecutivos comunes, las «comunidades o asociaciones concordatarias», a las que los cantones atribuyen competencias decisorias sobre materias concretas de naturaleza administrativa y normativa con rango reglamentario ${ }^{11}$.

Se trata del régimen más similar al regulado en el artículo 145 de la Constitución española.

\subsection{República Federal de Austria}

El artículo 15 de la Constitución austríaca autoriza los convenios entre Länder «en materias de su propio ámbito de aplicación y deberán ponerse inmediatamente en conocimiento del Gobierno Federal». A estos

\footnotetext{
9 Alberti Rovira, E.: Federalismo..., cit., pp. 368-369, 487 y ss.

10 Menéndez ReXach, A: Los convenios entre Comunidades Autónomas, Madrid, 1982, pp. 79 y ss. Alberti Rovira, E.: Federalismo..., cit., pp. 414-415.

11 Alberti Rovira, E.: Federalismo..., cit., pp. 418-424.
} 
convenios se aplican los principios del derecho internacional, aunque subordinados a las leyes constitucionales de los Estados firmantes dictadas por acuerdo. Pueden afectar a materias puramente administrativas o propias de la legislación, y se utilizan para su aprobación leyes o reglamentos.

Aunque no son frecuentes las instituciones comunes, existe una «Oficina de coordinación de los Länder», con funciones deliberantes y consultivas, sin facultades ejecutivas propias ${ }^{12}$.

\subsection{República italiana}

En Italia no existe una previsión constitucional, pero tal cooperación es una realidad basada en el concepto del interés interregional.

\section{La cooperación horizontal entre Comunidades Autónomas}

\subsection{El marco constitucional (art. 145 CE)}

La cooperación horizontal entre Comunidades Autónomas se halla expresamente prevista en el artículo $145 \mathrm{CE}$, el cual, tras prohibir la federación entre Comunidades, posibilita la existencia entre ellas de «convenios para la gestión y prestación de servicios propios, que deberán ser comunicados a las Cortes. También contempla la normalización de «Acuerdos de cooperación entre Comunidades Autónomas (que) necesitarán la autorización de las Cortes Generales».

El precepto constitucional contempla dos instrumentos de cooperación horizontal que se diferencian tanto por su contenido material como por la forma de control sobre los mismos por parte de las Cortes Españolas. El precepto ha sido muy criticado por la doctrina, calificado como «escasamente feliz» y con «un extraordinario margen de imprecisión y una serie de interrogantes difíciles de resolver» ${ }^{13}$.

El apartado 1 se considera innecesario «pues parece obvio que el contenido de los vínculos federativos que algunas comunidades pudieran establecer entre sí no podría rebasar, en ningún caso, el ámbito

12 Menéndez Rexach, cit., pp. 54 y ss. Alberti Rovira, E.: Federalismo..., cit., pp. 424-426.

13 Entrena Cuesta, R: Comentario al artículo 145, en Comentarios a la Constitución, dirigidos por Garrido Falla, Madrid, 1980, p. 1.570. 
máximo de competencias que la propia Constitución reconoce a cada comunidad, con lo que no se cuestionaría la naturaleza unitaria del Estado. Por el contrario, la omisión de este principio limitativo de la voluntad autonómica de las regiones y nacionalidades habría permitido dotar al nuevo régimen de autonomías de una mayor flexibilidad, con el fin de que su funcionamiento práctico permitiera ir desvelando sus posibles errores e insuficiencias, preparando de este modo el camino hacia una nueva redistribución del poder político territorial en el momento histórico posterior, si, en efecto, las mencionadas insuficiencias del propio modelo unitario así lo aconsejaran» ${ }^{14}$.

El apartado 2 es criticado por sus insuficiencias e imprecisiones, así como por haber «dado un tratamiento harto precario y riguroso a una técnica que en los sistemas de autonomía es de curso corriente» ${ }^{15}$.

Una breve referencia al proceso constituyente nos puede explicar el precepto. Fue una enmienda de Alianza Popular la que propuso prohibir la «federación de regiones autónomas», invocando el artículo 13 de la Constitución de 1931, ante el riesgo de formación de bloques que atentarían a la personalidad e independencia de las regiones, lo que «constituiría un indudable peligro para la unidad nacional» (Enmienda 33 de D. Alberto Jarabo Paya). Fraga Iribarne invocó también la guerra de secesión americana ${ }^{16}$, sosteniendo que la federación «sería un gravísimo riesgo para la consolidación del sistema autonómico de un Estado regional... que sólo podrán poner en peligro los que quisieran llevarlo más allá... no hay federaciones entre regiones, resolución que han tomado todos los pactos federales y que ya en su día tomó la República». Pérez Llorca lo hizo con la guerra de los cantones suizos ${ }^{17}$. Por el contrario, los diputados y senadores nacionalistas y socialistas propusieron bien la desaparición del precepto, bien la búsqueda de fórmulas de cooperación. Para Letamendía se había cerrado el paso a la defensa del derecho de autodeterminación y al federalismo ${ }^{18}$. Para Marcos Vizcaya el establecimiento de un acuerdo federativo entre Comunidades no suponía modificar el Estado, rechazando el control de las Cortes para la cooperación entre Comunidades ${ }^{19}$. En sentido similar los representantes

14 Leguina Villa, J.: «Las Comunidades Autónomas», en el libro dirigido por PredieRi y García de EnTERría, La Constitución Española de 1978, Madrid, 1980, pp. 785-786.

15 MuÑoz Machado, S.: Derecho Público de las Comunidades autónomas, I, Madrid, 1982, p. 234.

16 Diario de sesiones, 88, 1978, pp. 3.269-3.270.

17 Diario de sesiones..., cit, pp. 3.264-3.265.

18 Diario de sesiones..., cit., pp. 3.260-3.261.

19 Diario de sesiones..., cit., p. 3.268. 
catalanes y comunistas. El debate acreditó la gran diferencia de concepciones del Estado entre la unitaria centralista, la unitaria regionalista y la federalista. En el debate está presente por alusiones la cuestión de «los Países Catalanes», así como el riesgo de «colonización» de unas regiones por otras, además del peligro de alteración del modelo territorial y de la unidad del Estado. Puede apreciarse que algunos de estos conceptos siguen siendo utilizados a pesar de la consolidación del modelo constitucional de Estado unitario regional, que no otra cosa es el autonómico.

Es curiosa la constante invocación que el partido más vinculado al régimen franquista hizo del artículo 13 de la Constitución de 1931, lo que constituye una de las muchas paradojas de la Historia, exponente de que en este aspecto no querían avanzar más que la República. Es lo cierto que la Constitución diseñó un modelo de Estado autonómico entre el unitarismo centralista del franquismo y el federalismo programático de la mayoría de los partidos democráticos, asumiendo de modo vergonzante los hechos nacionales con la diferenciación entre «nacionalidades y regiones» del artículo 2 .

La invocación del artículo 13 de la Constitución republicana tuvo tanto éxito que el apartado 1 del artículo 145 lo recoge literalmente, cambiando sólo el tiempo de verbo, el presente de aquélla («En ningún caso se admite») por el futuro («En ningún caso se admitirá la federación»), y la denominación de «regiones autónomas» por la de «Comunidades Autónomas».

Tampoco en el debate constituyente de la República la cuestión fue pacífica. El diputado Sr. Samper defendió la posibilidad de que provincias sueltas y convertidas en regiones pudieran fundirse en la antigua región que históricamente hubieran formado. Pero más interesante para nosotros y una demostración de otra paradoja de la Historia fue la protagonizada por la minoría vasco-navarra. Su enmienda propuso que se admitiera «la federación de regiones autónomas que sean limítrofes y llenen para ello los mismos requisitos constitucionales que se exigen para la formación de regiones autónomas». La enmienda estaba firmada por D. Joaquín Beunza, D. Tomás Domínguez Arévalo, conde de Rodezno, D. Francisco Basterrechea, D. Antonio de Pildain, D. Rafael Picavea, D. José Horn, D. Manuel Egileor, D. Julio de Urquijo y D. José Antonio de Aguirre ${ }^{20}$.

Para Leguina «con esta medida limitativa — que al igual que en la Constitución republicana está contemplando singularmente la cuestión

20 Diario de sesiones de las Cortes Constituyentes, 45, 25 septiembre 1931, pp. 1.2021.203 . 
planteada por las Comunidades de habla catalana- se pretende cerrar el paso a toda forma de federalización encubierta del Estado y a la posible creación de macrocomunidades políticas y económicas, dotadas de órganos comunes de autogobierno, que pudiesen alterar de facto el equilibrio político regional buscado por la Constitución e incluso la correlación de poderes entre el Estado y las nuevas macrocomunidades que pudieran crearse. Se trata, pues, de una medida de precaución que quiere ser coherente con el propio modelo de Estado unitario consagrado por la Constitución, pero que, a mi juicio, es innecesaria, parece obvio que el contenido de los vínculos federativos que algunas Comunidades pudieran establecer entre sí no podría rebasar en ningún caso el ámbito máximo de competencias que la propia Constitución reconoce a cada Comunidad, con lo que no se cuestionaría la naturaleza unitaria del Estado» ${ }^{21}$.

Es lo cierto que, a pesar de la prohibición de federación, la Constitución establece en su artículo 145.2 la posibilidad de que los Estatutos contemplen los acuerdos y convenios de cooperación entre las Comunidades, que, en todo caso, han de respetar la prohibición. No se habilita a las Comunidades para hacerlos, sino que se parte de su capacidad para convenir, como propia de la autonomía que se les reconoce, estableciéndose los requisitos de control por las Cortes Generales, a las que se convierte en garantes del cumplımiento de la prohibición.

El alcance de la prohibición de federación es límite máximo al ejercicio de la autonomía en la necesaria cooperación horizontal, impidiendo la configuración de un nuevo nivel político-institucional entre las Comunidades y el Estado, o la modificación del sistema constitucional de distribución de competencias, o la alteración de los ámbitos territoriales, o la transmisión a órganos o instituciones intercomunitarias de la titularidad de competencias, indisponibles por imperativo constitucional y estatutario. Siendo la cooperación la regla general, como manifestación del principio de autonomía y de la propia naturaleza del Estado, la prohibición debe ser la excepción. Por ello su aplicación debe ser restrictiva, en beneficio de la regla general. No se puede olvidar que los instrumentos de cooperación son medios de integración de las distintas estructuras de poder existentes en el Estado, por lo que debe rechazarse su valoración como elementos disgregadores y potenciadores de centros de poder frente al Estado. Esta concepción supone no haber asumido o entendido el modelo territorial que la Constitución ha dado al Estado español. Como ha dicho el Tribunal Constitucional en relación

21 Leguina Villa, J.: Las Comunidades..., cit., p. 785. 
con la coordinación, «persigue la integración de la diversidad de las partes o subsistemas en el conjunto o sistema, evitando contradicciones y reduciendo disfunciones que, de subsistir, impedirían o dificultarían respectivamente la realidad misma del sistema» (S.TC. 32/83).

El precepto contempla dos niveles de cooperación entre Comunidades, que son «corporaciones públicas de base territorial y de naturaleza política» (S.TC.14-7-1981), cuyo territorio es el límite de su competencia. La solución de los problemas comunes exige actuaciones conjuntas fuera del ámbito territorial de la Comunidad, que afectan a varias de ellas sobre el conjunto de sus territorios. El Tribunal Constitucional ha declarado que «la unidad política, jurídica, económica y social de España impide su división en campartimentos estancos y, en consecuencia, la privación a las Comunidades Autónomas de la posibilidad de actuar cuando sus actos pudieran originar consecuencias más allá de sus límites territoriales equivaldría necesariamente a privarles, pura y simplemente, de toda capacidad de actuación» (SS.TC. 184/81, 44/84, 165/85).

Para hacerlo posible el artículo 145 contempla, en primer lugar, los «convenios para la gestión y prestación de servicios propios de las mismas», a los que se denomina «convenios de colaboración», que se comunican a las Cortes Generales. En segundo lugar los «acuerdos de cooperación», cuyo contenido no se precisa, que al necesitar «autorización» de las Cortes, implican un mayor nivel que los primeros, y afectan a algo más que la citada «gestión y prestación de servicios». Si identificamos el contenido material de los convenios de colaboración con la «actividad administrativa», aquéllos se referirían a la misma en su producción y ejecución, dejando para los acuerdos de cooperación las actuaciones de orden político, tanto dentro como fuera del ámbito estatal e institucional, o legislativo 22 .

Junto a estos convenios y acuerdos, formalizados conforme a los procedimientos previstos en la Constitución, los Estatutos y los Reglamentos del Congreso y Senado, se admite la existencia de otros instrumentos, consistentes en «declaraciones conjuntas de intenciones o propósitos, sin contenido vinculante, o la mera exposición de directrices o líneas de actuación» (S.TC. 44/86), a las que se denomina «Protocolos» entre Comunidades. Para dicha sentencia el encuadramiento en una $\mathrm{u}$ otra categoría se ha de basar en «la naturaleza del documento y el carácter de sus cláusulas. Ciertamente hay algunas que por su amplia generalidad y su falta de contenido vinculante pudieran no alcanzar la

22 Menéndez ReXach, A: Los convenios..., cit., pp. 98 y ss. Aja y otros: Sistema jurídico de las Comunidades Autónomas, Madrid, 1985, pp. 435 y ss. 
naturaleza propia de un convenio... por no darse en el documento aprobado el «carácter operativo» propio de los convenios... Basta la comprobación de que su texto contiene compromisos de actuación en sentido determinado».

\subsection{El régimen de los convenios de colaboración y los acuerdos de cooperación en el Estatuto Vasco y el Amejoramiento del Fuero de Navarra}

En el artículo 22 del Estatuto Vasco se contemplan los convenios y acuerdos, conforme al artículo 145 de la Constitución. También hay una previsión específica que sólo puede estar referida a Navarra en el apartado 2 cuando dice que «la Comunidad Autónoma podrá celebrar convenios con otro territorio histórico foral para la gestión y prestación de servicios propios correspondientes a las materias de su competencia...».

Esta posibilidad fue introducida por una enmienda del Sr. Alzaga, de la UCD, «inspirada en la necesidad de observar la singularidad de las relaciones que, evidentemente, mantiene y debe mantener la Comunidad Autónoma con el colindante territorio histórico-foral...». Territorio que con tales condiciones de colindancia y naturaleza sólo podía ser la Comunidad Foral de Navarra. Así lo confirmaron en el debate los señores Alavedra («el artículo salva perfectamente el tema de Navarra»), Martín Toval («está apuntado claramente el caso de Navarra») y Solé Tura («deja intacta la posible relación existente entre la C.A. de Euzkadi y el territorio foral»).

En Navarra el «proyecto de Bases de Negociación para el Amejoramiento del Fuero», que aprobó la Diputación Foral el 27 de diciembre de 1979, contempló la celebración de «convenios con la Comunidad Autónoma del País Vasco, o con cualquiera de los territorios históricos que la integran...». Apoyando una enmienda conjunta del PSOE y UCD en la que se mantenía esta posibilidad, el portavoz socialista articuló dichos convenios en el marco de las relaciones entre Navarra y el País Vasco, con mayor trascendencia que otros acuerdos: «...pretendemos también resolver un problema político... que existe en este pueblo...». «En Navarra hay un sector del pueblo —nosotros creemos que no es un sector mayoritario del pueblo, pero que es un sector de nuestro pueblo- que tiene una identidad vasca frustrada hoy; que a eso queremos responder, sin quebrar la voluntad de la mayoría del pueblo, con el convenio que aquí admitimos como vía, pero que si las futuras generaciones entienden que de la misma manera... pues si en esa evolución de 
nuestro pueblo se realiza su nueva conciencia... y es la integración en otro poder legislativo y en otro poder ejecutivo, nosotros no le pondremos puertas a nuestro pueblo». El mismo portavoz dijo en el debate del dictamen: «...no reconocer que debe haber unas relaciones especiales con la Comunidad Autónoma Vasca tiene que ser fruto de la ignorancia o tiene que ser fruto de no reconocer la evidencia de la voluntad de una parte de nuestro pueblo. Es decir, que en primer lugar los convenios vienen a incorporar a la vía institucional de Navarra aquellos sectores de nuestro pueblo que mantienen, y además frustradamente, su vocación vasca en Navarra...»

Fue interesante la afirmación de autonomismo que hizo el portavoz de la UCD, Sr. Astrain, cuando dijo que tales convenios «reafirman más nuestra personalidad, reafirman más nuestro deseo de autogobierno y reafirman más nuestra posibilidad no de diferenciación caprichosa con todos... nosotros creemos que se reafirma su propia personalidad cuando desde esta personalidad podemos establecer Convenios con los demás pueblos de España».

El artículo 70 LORAFNA hace una referencia específica a los convenios con la Comunidad Autónoma Vasca, diferenciándola de las demás Comunidades limítrofes, y reduciendo el plazo de comunicación a las Cortes respecto al régimen general. También existe una alusión diferenciada por lo que se refiere a los acuerdos de cooperación. Ello con independencia de la previsión constitucional (D.T. ${ }^{\text {a }} 4{ }^{\text {a }}$ ), recogida en el artículo 2.2 del Estatuto Vasco y en la disposición adicional 2. ${ }^{a}$ LORAFNA, del posible acuerdo para la incorporación de Navarra a la C.A. Vasca.

Estos convenios y acuerdos son objeto de control parlamentario interno, que en el caso de Navarra precisa la autorización del Parlamento al Gobierno. El control parlamentario externo corresponde a las Cortes Españolas, conforme el artículo 145 citado, bien por la comunicación en el caso de los convenios o por la aprobación en los acuerdos.

\section{La búsqueda de un marco de cooperación entre ambas Comunidades}

Hemos visto cómo el marco constitucional y estatutario posibilitan, en congruencia con el modelo político del Estado, la cooperación entre ambas Comunidades. Pero su configuración en la realidad de las instituciones sólo puede ser posible si existe voluntad política en los gobiernos y los parlamentos conceden las autorizaciones pertinentes, medio de control de su acomodación al régimen legal y al límite máximo que representa la prohibición de federación del apartado 1 del artículo 145 CE. 
La posibilidad de articular este marco de cooperación ha tenido distintos momentos desde su establecimiento estatutario, habiendo sido concebido, incluso, como un medio de dar satisfacción a las demandas de una parte de la sociedad navarra. Así lo reflejó el portavoz socialista en el debate de las Bases y texto de la LORAFNA, como se ha expuesto, considerándolo como una tercera vía entre la integración total, defendida por una parte minoritaria, y la separación total: «una vía que es la de la separación total de Navarra respecto a la CAV... Existe otra vía que es la de la integración plena..., es decir, su incorporación a ese Estatuto, su incorporación a esa Comunidad, a ese Parlamento y a ese Gobierno... y, finalmente, está la vía... de los convenios entre Navarra y la CAV... nos parece que no reconocer que debe haber unas relaciones especiales con la CAV tiene que ser fruto de la ignorancia o tiene que ser fruto de no reconocer la evidencia de la voluntad de una parte de nuestro pueblo... que mantienen, y además frustradamente, su vocación vasca en Navarra..., ¿qué es mejor, disolver una Comunidad, en este caso la Foral de Navarra, en la Comunidad estatutaria vasca o llegar a una fórmula de encuentro que reconozca la realidad institucional de esas dos Comunidades, que a nadie se le impida gobernar en su propia casa y que se busque el lazo de entendimiento para llegar a hacer en común lo que ambas Comunidades quieran poner en común?... Nosotros creemos que reconocer hoy esa realidad y reconocer esa vía es lo más acertado para Navarra y que responde más a la doble voluntad que existe en este pueblo» ${ }^{23}$.

Antes de ese debate parlamentario, en una mesa redonda celebrada el 2 de diciembre de 1978, el fundador de UPN, D. Jesús Aizpún, afirmó: «El hecho de que Navarra se divida, en la proporción que sea, puede conducir a una fatal convivencia. Y entonces diría que es preciso llegar a algún tipo de conexión que no supusiera la integración en Euzkadi, que no nos gusta, pero sí llegar a algún tipo de colaboración para satisfacer la ambición de quienes propugnan la integración... Hoy, estamos... de acuerdo en estudiar alguna fórmula que pueda para nosotros impedir la pérdida de la identidad de Navarra y quizás para ellos, algún tipo de conexión...» ${ }^{24}$.

Pocas fechas después, en el trámite del Anteproyecto de Estatuto de Autonomía del País Vasco, el partido político «Unión Nacional Española», de la coalición Alianza Popular, presentó el 15 de diciembre

23 Diario de sesiones del Parlamento Foral de Navarra, 1, 20-8-1981, pp. 512-513.

24 Diario de Navarra, 3-12-1978. Citado por J. GORTARI: La transición política en Navarra, 1975-1979, Pamplona, 1995, p. 566. 
de 1978 una enmienda a la totalidad en la que se contemplaba la posibilidad de que cada Provincia o territorio histórico tuviera «derecho a celebrar convenios referentes a todas y cada una de las materias de su competencia, no sólo con las otras dos, sino con las demás Comunidades Autónomas limítrofes... así como a promover la creación de instituciones comunes de enlace entre las Comunidades contratantes» ${ }^{25}$.

En el debate parlamentario de las Bases del Amejoramiento el grupo parlamentario de UPN se abstuvo, aunque su portavoz adujo que estaban de acuerdo en el fondo, que su rechazo era por una razón formal, no de fondo, «porque bienvenidos sean los convenios» ${ }^{26}$. Esta postura la reiteró en el debate del dictamen ${ }^{27}$.

La Agrupación Socialista de Navarra publicó en julio de 1981 un folleto titulado «La Autonomía de Navarra», en el que sostuvo que «las relaciones de Navarra con la CAV no pueden estar presididas ni por el principio de la integración ni por el de la separación, sino por el principio de la vinculación o de la cooperación» ${ }^{28}$.

Consecuencia de tal principio y en el marco de la LORAFNA, «Navarra debe proceder al establecimiento de una vinculación con la CAV, que sin mengua ni perjuicio de la personalidad, la autonomía y la ordenación institucional de cada una de ellas, permite resolver conjuntamente todas las cuestiones de interés común». El medio serían los convenios y acuerdos contemplados por el artículo 22 del Estatuto vasco, que también serán recogidos en la LORAFNA (punto 35).

En el «Acuerdo de Cooperación» se incluiría «la creación de un organismo intercomunitario que podría denominarse Consejo VascoNavarro... marco institucional adecuado para la elaboración de convenios concretos para la gestión y prestación de servicios en materia de educación, cultura, sanidad, comunicaciones, etc., y la adopción de resoluciones en materias de interés común». El Consejo estaría dotado de dos órganos. La Comisión Permanente, integrada por los Presidentes, a los que podrían acompañar miembros de sus respectivos gobiernos. El Pleno, integrado por los miembros de la Comisión Permanente, y por un número igual de miembros de ambos Parlamentos. «Dada su naturaleza de organismo intercomunitario, el Consejo Vasco-Navarro debería adoptar sus acuerdos y resoluciones de mutuo acuerdo entre

\footnotetext{
25 Tamayo Salaverría, V. y C.: Fuentes documentales y normativas del Estatuto de Guernika, Vitoria, 1981, p. 505.

26 Diario de sesiones del Parlamento Foral, 18, 9-6-1980, pp. 404-405.

27 Diario..., cit., pp. 513-514.

28 Punto 34, pp. 25-26.
} 
los representantes de ambas Comunidades y sin perjuicio de las competencias de las respectivas instituciones ya que, en caso contrario, estaríamos ante una institución supracomunitaria y ello no sería constitucional. En definitiva, el Consejo Vasco-Navarro cumpliría dentro de su ámbito, una función análoga a la que cumplen algunas instituciones de carácter internacional: servir de marco para una política de cooperación entre los Estados, sin perjuicio de la independencia de estos» (punto 36).

En el acuerdo de Gobierno para la Comunidad Autónoma Vasca, firmado entre el PNV y el PSE en enero de 1987, el punto 10 comprometía al Gobierno a propiciar una «política de entendimiento y estrechamiento de lazos y vínculos con el territorio hermano de Navarra, mediante los cauces de celebración de convenios y acuerdos de cooperación en las diversas materias de interés común, tanto económicas como culturales. Asimismo, el Gobierno Vasco estudiará y tratará en su caso con las Autoridades e Instituciones navarras la posibilidad de establecer algún órgano común permanente, de acuerdo con las posibilidades legales existentes».

Como consecuencia del anterior acuerdo, el Grupo Popular en el Parlamento de Navarra presentó una moción para que éste declarase que «el Gobierno de Navarra carece de competencia para negociar con el Gobierno de Euzkadi el establecimiento de ningún órgano permanente entre ambas Comunidades». El mismo grupo enmendó su moción cambiando radicalmente su propuesta. En primer lugar «valora positivamente la actitud de la Comunidad Autónoma del País Vasco favorable a la normalización de convenios de cooperación entre ambas Comunidades». Además propuso declarar que «el Parlamento de Navarra considera que resulta conveniente el estudio de las posibilidades legales que permitan la creación de un "órgano común permanente", para servir de cauce de encuentro entre los Gobiernos de ambas Comunidades en orden a la formación de futuros convenios de cooperación en materias de interés común, siempre que ello no implique la atribución al referido órgano de funciones de representación política o de carácter decisorio y vinculante para ambas Comunidades». Así fue aprobado por el Parlamento en sesión de 12 de marzo de $1987^{29}$.

El Acuerdo para la formación del Gobierno de Navarra entre el PSN-PSOE y EA de 26 de julio de 1991 contempló «las políticas de coordinación y cooperación con la CAV al objeto de garantizar un desarrollo coherente y equilibrado en aquellas materias en las que ambas

29 BOP, 22, 17-3-1987 
Comunidades tienen intereses comunes», así como promover «la creación de una comisión intergubernamental de carácter permanente que mantendrá reuniones periódicas y cuyas decisiones se harán efectivas, en su caso, mediante los instrumentos jurídicos previstos en la Constitución, la LORAFNA y el Estatuto».

En el programa electoral del PSN-PSOE de 1995, se propuso la creación de una «Comisión intergubernamental de carácter permanente con el Gobierno vasco», como un medio de consolidación del autogobierno y de integración y cohesión de la sociedad navarra, rechazando el fundamentalismo «que pretende profundizar en la configuración de dos comunidades políticas enfrentadas».

En el Pacto de Gobierno firmado el 4 de julio de 1995 entre PSNPSOE, CDN y EA existía un compromiso de establecer «unas relaciones especiales y permanentes con la Comunidad Autónoma Vasca, por razones históricas y por la existencia de cuestiones comunes». Se invocó la política de coordinación y cooperación entre ambos Gobiernos, así como el compromiso de crear una Comisión Intergubernamental permanente... cuyas decisiones se harán efectivas mediante los instrumentos jurídicos previstos en la Constitución, la LORAFNA y el Estatuto.

De acuerdo con el citado pacto de gobierno se firmó el 25 de octubre de 1995 un protocolo entre el Lehendakari del Gobierno Vasco y el Presidente del Gobierno de Navarra en el que acordaron «propiciar y desarrollar, en el marco de sus respectivas competencias, relaciones de colaboración permanente con el objetivo de:

1. Incrementar la cooperación en aquellas materias en las que las dos Comunidades tienen intereses comunes, especialmente en materias educativas, culturales, de política lingüística, económicas, sanitarias, de ordenación territorial, infraestructuras, medio ambiente y medios de comunicación.

2. Armonizar sus políticas respectivas en las áreas apuntadas.

3. Concertar la definición y puesta en marcha de proyectos de interés común.

4. Fomentar todas las relaciones de colaboración que se susciten entre las instancias públicas y privadas de ambas Comunidades.

Para hacerlo posible manifestaron la intención de ambos gobiernos de «consensuar una fórmula de colaboración que establezca los mecanismos de coordinación e impulso de las relaciones entre ambas Comunidades, en el marco de la Constitución, del Estatuto y de la LORAFNA, incluyendo un órgano Permanente de Encuentro, cuyas decisiones se harán efectivas mediante los instrumentos jurídicos previstos en el ordenamiento vigente». 


\section{El Acuerdo de Cooperación entre la Comunidad Autónoma Vasca y la Comunidad Foral de Navarra de mayo de 1996}

Con base en el protocolo anterior se elaboró el Acuerdo de Cooperación, que fue aprobado por el Gobierno de Navarra el día 13 y por el Gobierno vasco el día 14 de mayo de 1996.

El preámbulo fundamenta el convenio «no sólo en una mera relación de vecindad... sino que hunde sus raíces en una afinidad histórica, cultural y social que ha tenido diversas manifestaciones a través de los tiempos». Se aludió a la creación en 1918 de la Sociedad de Estudios Vascos-Eusko Ikaskuntza y la Real Academia de la Lengua Vasca-Euskaltzaindia. Se destacó que la cooperación se realizará en el marco constitucional y estatutario, «desde el total respeto a la voluntad de los ciudadanos de cada Comunidad», lo que implica «el reconocimiento mutuo de las estructuras político-administrativas actualmente vigentes», que han permitido acuerdos y colaboración en distintas áreas. También se invocó la cooperación en marcos europeos como el Protocolo Aquitania-Euskadi-Navarra, la Comunidad de Trabajo de los Pirineos, el Comité de las Regiones, la Asamblea de Regiones de Europa, el Arco Atlántico, la Conferencia de las Regiones de Sur de Europa Atlántica y la Asociación de Regiones Fronterizas.

En la parte dispositiva, el artículo $1 .^{\circ}$ dispuso que la finalidad del Acuerdo de Cooperación era «establecer e impulsar un marco permanente de cooperación en aquellas materias que sean de su competencia, según el ordenamiento jurídico vigente», que el preámbulo identificó con la Constitución, el Estatuto y la LORAFNA.

El artículo 2. ${ }^{\circ}$ enumeraba los objetivos del acuerdo:

10. Trabajar conjuntamente en la consecución de una Europa en la que las Regiones tengan un papel destacado, para lo cual propiciarán el cumplimiento de los fines de las asociaciones y foros europeos, de carácter transfronterizo o de más amplio espectro de las que forman parte.

Para hacer posible el «marco permanente de cooperación» (art. 1), que permita el cumplimiento de los objetivos (art. 2), se crea un «órgano permanente de encuentro, foro estable y permanente de relación que sirva de instrumento de coordinación e impulso en las materias de interés común para ambas Comunidades» (art. 3). El órgano actuará desde la «igualdad y respeto mutuo» (preámbulo $6 .^{\circ}$ ), como medio para «coordinar sus políticas respectivas... en el marco de los acuerdos que se adopten» (art. 2.2), conforme al ordenamiento jurídico vigente (preámbulo $3 .^{\circ}$ y art. 1). Sus acuerdos se instrumentarán a través de 
convenios de colaboración y acuerdos de cooperación conforme al ordenamiento vigente, constituido por los artículos 145.2 CE, 22 EAPV y 70 LORAFNA (art. 5.6).

La estructura del órgano estará integrada por el Consejo, el Secretariado Permanente y las Ponencias técnicas.

El Consejo, formado por los Presidentes y tres miembros de cada uno de los Gobiernos, «constituye la máxima representación política», está copresidido por los Presidentes, quienes ostentan la representación de las Comunidades y la ordinaria del Estado en cada una de ellas. Su competencia es la elaboración del programa de actuaciones y objetivos, adoptando acuerdos que pueden precisar convenios de colaboración o acuerdos de cooperación. Nada especifica sobre la forma de adopción de acuerdos que, necesariamente y por su propia naturaleza, deben basarse en el consenso.

1. Cooperación en materias culturales, de política lingüística y medios de comunicación; educativas; económicas, tributarias y administrativas; de desarrollo comercial, industrial y turístico; de agricultura y medio ambiente; de infraestructuras y ordenación territorial; sanitarias; de protección civil y de seguridad; de acción exterior.

2. Coordinación de las respectivas políticas en las materias de su competencia, en el marco de los acuerdos que se adoptan.

3. Definir y poner en marcha iniciativas y proyectos conjuntos, para lo cual se desarrollará la asistencia mutua en la preparación, articulación, seguimiento y evaluación de dichas acciones.

4. Promover el intercambio de información institucional entre las Administraciones sobre sus respectivas políticas en los distintos ámbitos en los que ejercen su labor de gobierno y sobre cualquier materia de interés común.

5. Realizar estudios e investigaciones de forma conjunta en los ejes de cooperación citados.

6. Impulsar la colaboración y el mutuo auxilio en la defensa de las singularidades propias de los régimenes forales de ambas Comunidades.

7. Proporcionar proyectos de colaboración para la formación del personal al servicio de las distintas Administraciones.

8. Apoyar las relaciones culturales, sociales y económicas entre agentes del sector privado de las dos Comunidades, comprometiéndose activamente a hacer extensiva la colaboración a las Entidades Locales, y a ámbitos como las Universidades, Cámaras de Comercio, Colegios Profesionales y Asociaciones Culturales. 
9. Contribuir a estrechar las relaciones con sus colectividades en el exterior, promoviendo su desarrollo a través de los Centros o Casas existentes.

El Secretariado Permanente, presidido por dos miembros del Consejo y tres representantes de cada Gobierno, es órgano de preparación y seguimiento del trabajo del Consejo, que coordina e impulsa el desarrollo de las actuaciones en las respectivas administraciones.

Las Ponencias Técnicas, de carácter paritario, cuya constitución es decidida por el Consejo o el Secretariado Permanente, realizarán «el estudio específico de las acciones sectoriales en las que existe un interés compartido por ambas Comunidades».

El acuerdo aprobado por los Gobiernos fue también autorizado por los respectivos Parlamentos y remitido a las Cortes Generales para que otorgaran su autorización, conforme al artículo 145.2 CE.

No voy a entrar en los detalles del proceso que tuvo lugar en el Senado hasta su resolución de devolución. Es lo cierto que la causa de tal decisión no se basó en que la Cámara Baja hubiese llegado, en su análisis del documento, a la conclusión de que el mismo violase la prohibición de federación entre Comunidades que, como límite máximo a los acuerdos de cooperación, establece el apartado 1 del citado artículo 145 CE. La causa directa fue la petición formulada por el nuevo Gobierno de Navarra, formado por UPN, que retiró del trámite parlamentario el acuerdo entre ambas Comunidades. Esta decisión fue adoptada por un gobierno minoritario y sin el consentimiento del Parlamento de Navarra, quien lo había autorizado por mayoría absoluta.

Aunque en algún momento se hayan invocado argumentaciones jurídicas, se hizo sin fundamento ni fuerza. Navarra no perdía sus competencias, transfiriendo al órgano la titularidad de las mismas, porque esto es imposible y no tiene ningún punto de apoyo. Ni el acuerdo implicaba la federación de las Comunidades, porque ni se transfería la titularidad de competencias, ni se creaba una nueva unidad política entre el Estado y las actuales Comunidades, ni se configuraban órganos propios supraordenados a los de las Comunidades, sino un marco de colaboración y cooperación conforme al ordenamiento constitucional vigente, instrumentado por un órgano de encuentro para hacerlas posible. $\mathrm{Ni}$ el órgano puede ser calificado de Dieta, propia de las Confederaciones de Estados, porque falta la premisa básica, que es la existencia de soberanías estatales que se coordinan y actúan conjuntamente en ámbitos concretos como la defensa y las relaciones exteriores, competencias que, sin duda, no corresponden a estas Comunidades. El acuerdo se había configurado en condiciones similares al de las comunidades del 
arco mediterráneo, que había sido aprobado por las Cortes Españolas el 1 de junio de 1995. También en este caso se había creado un «marco estable de cooperación», dotado de «Comisiones de Cooperación», «Comisiones Técnicas de Coordinación» y una «Secretaría Técnica Permanente».

La escasa solidez de los argumentos de orden jurídico constitucional hizo que éstos fueran de inmediato sustituidos por el voluntarismo político, que necesita mucho menos rigor, es más propicio a la demagogia y a las reacciones emotivas y primarias. Por eso desde la derecha, olvidando sus iniciativas y declaraciones anteriores, se inició una cruzada contra el acuerdo de cooperación, como medio para atacar al gobierno tripartito que lo había hecho posible. Se volvieron a invocar los viejos fantasmas del pasado, como el anexionismo vasco, argumentando que tal acuerdo era el primer paso para la integración de Navarra en la CAV, que para cooperar con ésta no hacen falta ni acuerdos ni, mucho menos, órganos permanentes de encuentro, que Navarra perdía su identidad porque ponía su autogobierno en manos ajenas, etc. Todo, por muy simple que fuera, era argumento válido en la cruzada contra el gobierno tripartito, utilizando como excusa el acuerdo de cooperación.

Hay que reconocer que desde la CAV y desde el nacionalismo vasco se dieron argumentos para esa cruzada. Se transmitió la idea de que se trataba de un logro histórico, de un paso decisivo para un nuevo proceso de unidad territorial, etc. Los argumentos partidistas para rentabilizar el contenido del acuerdo de cooperación, más allá de su auténtico significado y alcance real en el marco constitucional, fueron utilizados por los navarristas radicales para apoyar su argumentación. Frente a sus burdos argumentos, la cita de declaraciones desde el nacionalismo vasco los convertían en auténticas verdades, porque eran los enemigos de la identidad y el autogobierno de Navarra quienes ponderaban en beneficio de sus objetivos lo que aquéllos criticaban. No cabía mejor apoyo. Intentaron una movilización social que no consiguieron, a pesar de los muchos medios de todo tipo que aplicaron, de las campañas y apoyos de algunos sectores influyentes por su poder económico o mediático.

Volvieron al discurso político de 1978, como si no hubiese ni Constitución, ni Estatuto, ni LORAFNA. Como si el futuro de Navarra estuviese en manos de alguien que no fuesen los propios navarros. Como si en dichas normas no se contemplase, expresamente, cuál es el camino legal e institucional para que los navarros decidan libremente sobre su futuro. Los mismos que se opusieron a la disposición Transitoria $4 .^{\mathrm{a}} \mathrm{de}$ la Constitución porque no reconocen al pueblo navarro su derecho a determinarse en cuanto al modelo político y territorial que deseen, volvían a invocar no esa garantía institucional de la libertad, sino el miedo 
al enemigo, al invasor, al que quiere imponerse a un pueblo sin contar con él, que es, exactamente, lo que ellos mismos tratan de hacer. En vez de tranquilizarlo, explicando que nadie puede imponer su voluntad al pueblo navarro, que sólo en sus manos mediante referéndum está su destino, lo ocultan y excitan los temores, no le informan, porque saben que un pueblo sin miedo e informado no es susceptible de ser manipulado, que es lo que ellos buscan, porque en el miedo del pueblo a la libertad está la garantía de su dominación sobre el mismo.

Entre unos y otros han hecho fracasar el acuerdo, que sólo era un instrumento para desarrollar el autogobierno, en el marco constitucional, medio para el reconocimiento de cada una de las realidades institucionales diferenciadas existentes, cooperación leal en plano de igualdad, camino para la convivencia entre pueblos con su propio proyecto político e institucional que, desde sus diferencias, buscan el encuentro en todo lo que les une en benéfico común. Como ha dicho recientemente Jesús Eguiguren, secretario general del PSE de Guipúzcoa, «los grandes perdedores han sido los navarristas: si yo fuera navarrista, me gustaría que el nacionalismo vasco reconociera a Nafarroa en un plano de igualdad, como proponía el órgano. Ahí el que cedía era el nacionalismo al reconocer unas relaciones de igualdad. El navarrismo ha perdido una oportunidad histórica» ${ }^{30}$.

Como dijo Gandhi, «el mérito no es del que apunta con el dedo al hombre valiente que tropieza o al pionero de grandes obras, porque podría haber hecho mejor las cosas. El mérito es del que se atreve a abrir caminos inexplorados con entusiasmo y con entrega, del que da su vida por una causa noble, del que en el mejor de los casos recoge al fin el triunfo anhelado, o del que, en el peor de los casos, si fracasa, al menos fracasa en una causa noble, jugándose su vida $y$, por tanto, nunca será colocado con esas almas frías y calculadoras que no conocen ni el fracaso ni la victoria».

Muchas gracias. Mila esker.

Universidad de Deusto, Bilbao, 17 de febrero de 1997

30 DEIA, 3-2-1997, p. 14. 